\title{
Protective effects of icariin on human vascular endothelial cells induced by oxidized low-density lipoprotein via modulating caspase-3 and Bcl-2
}

\author{
YANWU HU ${ }^{1,2}$, HAITAO LI $^{3}, \mathrm{KAI} \mathrm{LIU}^{4}$, YANG ZHANG ${ }^{4}$, LIQUN REN $^{4}$ and ZHIMIN FAN ${ }^{1}$ \\ ${ }^{1}$ Department of Breast Surgery, The First Hospital, Jilin University, Changchun, Jilin 130021; \\ ${ }^{2}$ Department of Traditional Chinese Medicine, School of Pharmaceutics and Food Science, \\ Tonghua Normal University, Tonghua, Jilin 134002; ${ }^{3}$ Department of Pharmacy, The Affiliated Hospital of \\ Changchun University of Chinese Medicine; ${ }^{4}$ Department of Experimental Pharmacology and Toxicology, \\ School of Pharmaceutical Science, Jilin University, Changchun, Jilin 130021, P.R. China
}

Received September 30, 2017; Accepted February 2, 2018

DOI: $10.3892 / \mathrm{mmr} .2018 .8717$

\begin{abstract}
Icariin belongs to the family of flavonoids that is extracted from Epimedium brevicornum Maxim, and exhibits antioxidative, antitumorigenic, antiosteoporotic, immunoregulatory and antiatherosclerotic properties. To understand the mechanisms underlying the antiatherosclerotic properties of icariin, the present study investigated the effects of icariin on human vascular endothelial cells (HUVECs) following treatment with oxidized low-density lipoprotein (ox-LDL). Thus, following pretreatment with icariin at four various concentrations $(0,10,20$ and $40 \mu \mathrm{M})$, HUVECs were stimulated with ox-LDL $(100 \mu \mathrm{g} / \mathrm{ml})$. The viability of cells was evaluated via an MTT assay and flow cytometry was performed to assess apoptosis. Additionally, the protein and mRNA expression levels of apoptosis regulator Bcl-2 (Bcl-2) and caspase- 3 were determined by western blotting and reverse transcription-quantitative polymerase chain reaction. The findings of the present study indicated that icariin prevented injury and apoptosis in HUVECs following ox-LDL treatment, in particular via the regulation of protein and mRNA expression levels of Bcl-2 and caspase-3.
\end{abstract}

\section{Introduction}

Atherosclerosis (AS) is chronic vascular inflammation (1) involving lumen narrowing and rigidity due to cholesterol and lipid accumulation $(2,3)$. Additionally, AS is associated with vascular endothelial damage, following which low-density

Correspondence to: Professor Zhimin Fan, Department of Breast Surgery, The First Hospital, Jilin University, 71 Xinmin Road, Changchun, Jilin 130021, P.R. China

E-mail: fanzmjlu@sina.com

Key words: apoptosis regulator Bcl-2, caspase-3, icariin, human vascular endothelial cell, injury, oxidized low-density lipoprotein lipoprotein (LDL) enters the subendothelial layer where it is oxidized (ox-LDL) and subsequently consumed by scavenger receptors. Consequently, monocytes are recruited and infiltrate the artery wall, where they differentiate into macrophages $(4,5)$. Thus, the ox-LDL-associated damage to vascular endothelial cells (VECs) is directly associated with the initiation and development of AS $(6,7)$.

Traditional Chinese Medicine has widely employed Epimedium brevicornum Maxim in 'tonifying kidney and strengthening bone' in China, Korea and Japan (8-10). Icariin $\left(\mathrm{C}_{33} \mathrm{H}_{40} \mathrm{O}_{15}\right.$; Fig. 1) is a pharmacologically active flavonoid extracted from E. brevicornum Maxim (11,12), with numerous pharmacological properties, including antiosteoporosis (13), antitumor (14), immunoregulation (15), anti-inflammation (5) and antioxidation (16). Icariin is additionally used to treat cardiovascular diseases and exhibits anti-atherosclerotic properties (17-21) that are associated with its protective effects on endothelial cells (17); however, the underlying mechanisms require further investigation. Thus, the present study analyzed the effects of icariin on ox-LDL-induced injury and apoptosis in human (HUVECs) by evaluating cell viability apoptosis and its associated genes and proteins, including caspase- 3 and apoptosis regulator $\mathrm{Bcl}-2$ (Bcl-2), in injured human HUVECs with or without treatment with icariin.

\section{Materials and methods}

Cell culture and treatments. HUVECs were purchased from the Cell Bank of the Type Culture Collection of the Chinese Academy of Sciences (Shanghai, China), and were seeded into 96-well plates at a density of $1 \times 10^{4}$ cells/well and incubated for $12 \mathrm{~h}\left(37^{\circ} \mathrm{C}, 5 \% \mathrm{CO}_{2}\right)$ in Dulbecco's modified Eagle's medium (DMEM; Gibco; Thermo Fisher Scientific, Inc., Waltham, MA, USA) containing 10\% fetal bovine serum (Hangzhou Sijiqing Bioengineering Material Co., Ltd., Hangzhou, China), $1 \%$ penicillin and $1 \%$ streptomycin (Sigma-Aldrich; Merck KGaA, Darmstadt, Germany). Following pretreatment with 0, 10, 20 and $40 \mu \mathrm{M}$ icariin (Sichuan Weike Biotechnology Co., Ltd., Chengdu, China) for $24 \mathrm{~h}$ at $37^{\circ} \mathrm{C}$, cells were 
treated for $24 \mathrm{~h}$ with $100 \mu \mathrm{g} / \mathrm{ml}$ ox-LDL (Guangzhou Yiyuan Biological Technology Co., Ltd., Guangzhou, China).

Viability of cells. Based on a previous report (17), the cells were maintained for $24 \mathrm{~h}$ in serum-free DMEM to achieve cell cycle synchronization prior to their treatments with icariin and ox-LDL. Following pretreatment with icariin and ox-LDL, MTT reagent $(0.5 \mathrm{mg} / \mathrm{ml})$ was added to the cells at a density of $1 \times 10^{4}$ cells/well and they were incubated for $4 \mathrm{~h}$ at $37^{\circ} \mathrm{C}$. Subsequently, the precipitate was dissolved in $150 \mu \mathrm{l}$ dimethyl sulfoxide, and the optical density of the supernatant was measured at a wavelength of $490 \mathrm{~nm}$.

Apoptosis. In the present study, the apoptotic ability was evaluated using an Annexin V fluorescein isothiocyanate (FITC) kit (Beijing Solarbio Science \& Technology Co., Ltd., Beijing China), FACSCalibur (BD Biosciences, San Jose, CA, USA) and ModFit LT V3.3.11 software (Verity Software House Inc., Topsham, ME, USA). Cells were washed with PBS and centrifuged for $5 \mathrm{~min}$ at $800 \mathrm{xg}$ at $4^{\circ} \mathrm{C}$, and the treated cells were resuspended in $200 \mathrm{ml} 1 \mathrm{X}$ Annexin binding buffer and harvested. Subsequently, cells were stained with $5 \mathrm{ml}$ propidium iodide (PI; Sigma-Aldrich; Merck KGaA) and $2.5 \mathrm{ml}$ Annexin V/FITC, and protected from light for $15 \mathrm{~min}$ at $37^{\circ} \mathrm{C}$.

Western blotting. HUVECs were seeded into 6-well plates at a density of $1 \times 10^{4}$ cells/well, treated as aforementioned, harvested and lysed for $30 \mathrm{~min}$ in ice-cold radioimmunoprecipitation assay lysis buffer (Beyotime Institute of Biotechnology, Jiangsu, China). Following centrifugation for $20 \mathrm{~min}$ at $13,000 \mathrm{x} \mathrm{g}$ and $4^{\circ} \mathrm{C}$, the supernatants were analyzed using a bicinchoninic acid assay. Equal amounts of protein samples $(50 \mu \mathrm{g})$ were loaded onto a 15\% SDS-PAGE and electrotransferred to polyvinylidene difluoride membranes, which were blocked with 5\% fat-free milk for $1 \mathrm{~h}$ at room temperature. At $4^{\circ} \mathrm{C}$ membranes were incubated with rabbit anti-human monoclonal antibodies against caspase-3 (1:1,000; cat. no. ab23021; Abcam, Cambridge, UK), anti-Bcl-2 (1:1,000; cat. no. ab47482; Abcam) or anti-GAPDH (1:1,000; Sigma-Aldrich; Merck KGaA; cat. no. sab4300645) overnight, followed by horseradish peroxidase-labeled goat anti-rabbit secondary antibody (1:5,000; cat. no. sc45101; Santa Cruz Biotechnology, Inc., Dallas, TX, USA) for $1 \mathrm{~h}$ at ambient temperature. The bands were visualized by enhanced chemiluminescence/X-ray films (GE Healthcare, Little Chalfont, UK) and were analyzed using ImageJ version 1.46 (National Institutes of Health, Bethesda, MD, USA).

Reverse transcription-quantitative polymerase chain reaction $(R T-q P C R)$. Total RNA was extracted from HUVECs with TRIzol $^{\mathrm{TM}}$ reagent (Invitrogen; Thermo Fisher Scientific, Inc.). A total of $5 \mu \mathrm{g}$ total RNA was reverse transcribed using a PrimeScript RT Master Mix kit (Takara Biotechnology Co., Ltd., Dalian, China), and RT-qPCR was performed using SYBR $^{\circledR}$ Premix Ex Taq (Beijing Transgen Biotech Co., Ltd., Beijing, China) and the following program: Denaturing at $95^{\circ} \mathrm{C}$ for $10 \mathrm{sec}$, annealing at $60^{\circ} \mathrm{C}$ for $15 \mathrm{sec}$ and extension at $72^{\circ} \mathrm{C}$ for $30 \mathrm{sec}$ (40 cycles). GAPDH was used as a housekeeping gene. The following oligonucleotide primers were used: Caspase-3 forward, 5'-GTGGAATTGATGCGTGATG-3' and

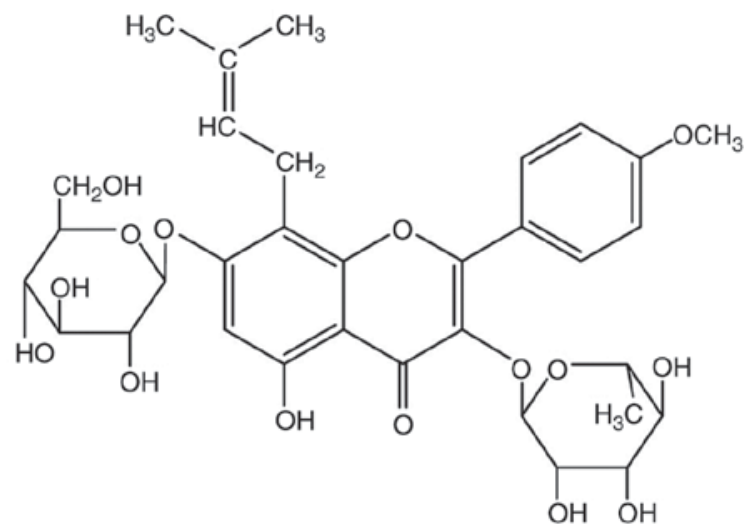

Figure 1. Chemical structure of icariin.

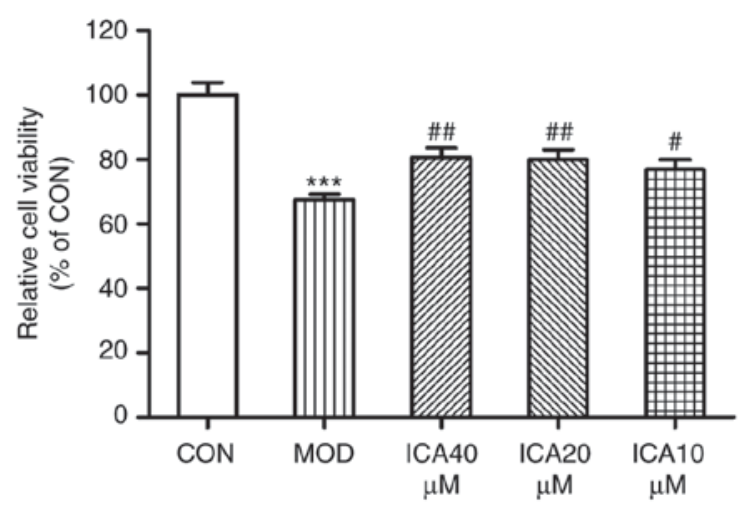

Figure 2. Protective effects of icariin in human vascular endothelial cells Cells were treated for $24 \mathrm{~h}$ with icariin $(0,10,20$ and $40 \mu \mathrm{M})$ followed by oxidized low-density lipoprotein $(100 \mu \mathrm{g} / \mathrm{ml})$. Based on the MTT assay, cell viability was significantly promoted by pretreatment with icariin. ${ }^{* * *} \mathrm{P}<0.001$ vs. CON; ${ }^{\text {P }}<0.05,{ }^{\#} \mathrm{P}<0.01$ vs. MOD. CON, control; ICA, icariin-treated group; MOD, oxidized low-density lipoprotein-simulated group.

reverse, 5'-GGAATCTGTTTCTTTGCATG-3'; Bcl-2 forward, 5'-GGTGCCACCTGTGGTCCACCT-3' and reverse, 5'-CTT CACTTGTGGCCCAGATAGG-3'; and GAPDH forward, 5'-GTTACCAGGGCTGCCTTCTC-3' and reverse, 5'-GAT GGTGATGGGTTTCCCGT-3'. Relative quantification was calculated using the $2^{-\Delta \Delta \mathrm{Cq}}$ method (22) and the results were normalized to those of GAPDH.

Statistical analysis. The SPSS 19.0 program (IBM, Corp., Armonk, NY, USA) was used. Each independent experiment was performed in triplicate. One-way analysis of variance followed by a Tukey's post-hoc analysis was used, and the data are presented as the mean \pm standard error. $\mathrm{P}<0.05$ was considered to indicate a statistically significant difference.

\section{Results}

Protective effects of icariin. To investigate whether icariin exerts a protective effect against injury, the present study analyzed the viability of HUVECs treated with ox-LDL via an MTT assay. Treatment with ox-LDL significantly decreased the viability of HUVECs compared with control cells (Fig. 2), while icariin mitigated this decrease. These findings suggested 

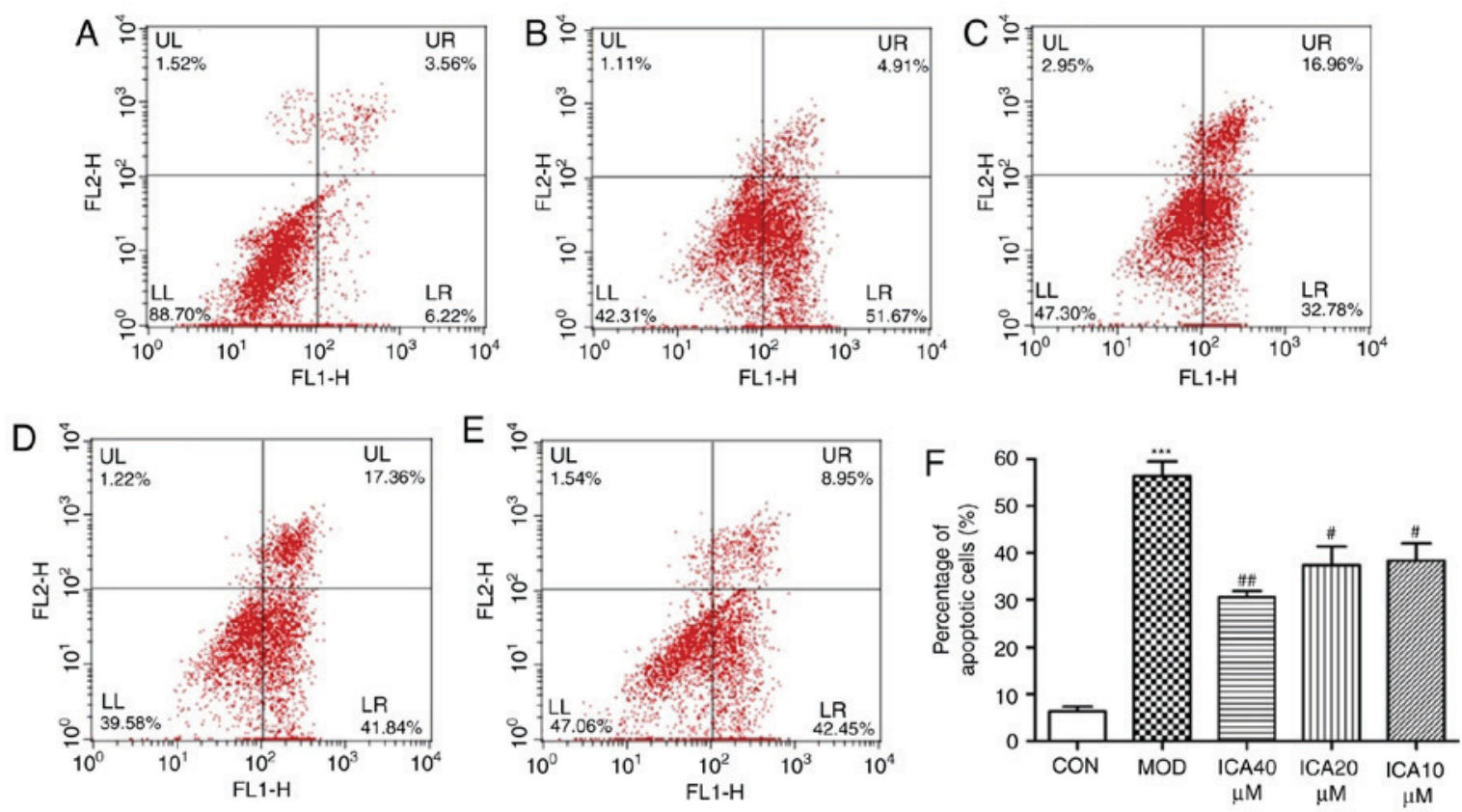

Figure 3. Antiapoptotic effects of icariin on HUVECs. Following $24 \mathrm{~h}$ pretreatment with icariin at different doses $(0,10,20$ and $40 \mu \mathrm{M})$, cells were stimulated with ox-LDL $(100 \mu \mathrm{g} / \mathrm{ml})$, and flow cytometry was used to determine the rate of apoptosis. (A) Representative results of control cells. (B) Representative results of HUVECs stimulated with ox-LDL. Representative results of icariin at (C) 10, (D) 20 and (E) $40 \mu \mathrm{M}$ in HUVECs stimulated with ox-LDL. (F) Percentage of early apoptotic cells following the indicated treatments. ${ }^{* * * *} \mathrm{P}<0.001$ vs. CON; ${ }^{*} \mathrm{P}<0.05$, ${ }^{\# \#} \mathrm{P}<0.01$ vs. MOD. HUVECs, human vascular endothelial cells; ICA, icariin-treated group; ox-LDL, oxidized low-density lipoprotein; MOD, ox-LDL-simulated group.

that icariin may have exerted protective effects against injury within HUVECs stimulated with ox-LDL.

Antiapoptotic effects of icariin. To determine the effect of icariin on cellular apoptosis, Annexin-V and PI double staining was performed. The present study investigated the apoptosis rate of HUVECs treated with ox-LDL using flow cytometry. The apoptosis rate significantly increased when HUVECs were treated with ox-LDL compared with the control group (Fig. 3). Additionally, pretreatment with icariin significantly mitigated this effect, the improvement was more significant at $40 \mu \mathrm{M}$ icariin compared with the other assayed concentrations. These findings indicated that icariin markedly inhibited apoptosis in HUVECs stimulated with ox-LDL.

Regulation of caspase-3 and Bcl-2 in HUVECs by icariin. To investigate the mechanism underlying the protective effects of icariin on ox-LDL-induced cellular apoptosis, the relative gene and protein expression levels of Bcl-2 and caspase-3 were quantified via RT-qPCR and western blot analysis, respectively. Treatment of HUVECs with ox-LDL significantly increased caspase-3 and decreased Bcl-2 expression at the protein (Fig. 4) and mRNA level (Fig. 5). Conversely, icariin pretreatment significantly suppressed these alterations. The results indicated that icariin exerts antiapoptotic effects by downregulating caspase- 3 mRNA and protein expression levels while upregulating those of Bcl-2.

\section{Discussion}

Previous reports have demonstrated the harmful effects of ox-LDL, which induced the apoptosis of endothelial cells (23). Furthermore, ox-LDL is involved in the pathogenesis of
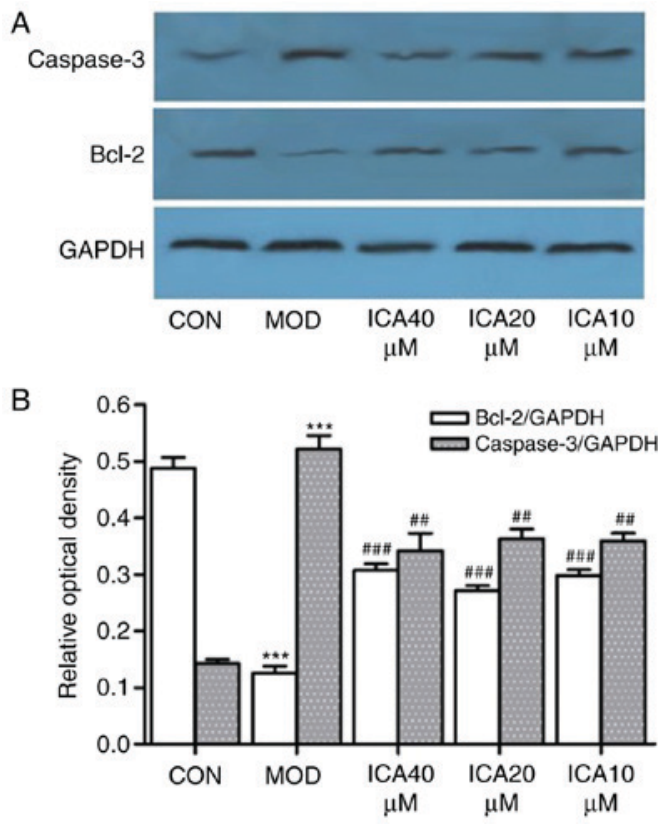

Figure 4. Icariin-induced regulation of caspase-3 and Bcl-2 protein expression in human vascular endothelial cells. Following pretreatment with icariin $(0,10,20$ and $40 \mu \mathrm{M})$, cells were treated with ox-LDL $(100 \mu \mathrm{g} / \mathrm{ml})$ for $24 \mathrm{~h}$, and the protein expression levels of caspase- 3 and Bcl-2 were detected by western blot analysis; as a loading control, GAPDH was used. (A) Expression of Bcl-2 and caspase-3. (B) Ratio of Bcl-2 and caspase-3 expression levels to control levels. ${ }^{* * * *} \mathrm{P}<0.001$ vs. $\mathrm{CON} ;{ }^{\# \#} \mathrm{P}<0.05,{ }^{\# \#} \mathrm{P}<0.01$ vs. respective MOD group. $\mathrm{Bcl}-2$, apoptosis regulator $\mathrm{Bcl}-2$; $\mathrm{CON}$, control; ICA, icariin-treated group; ox-LDL, oxidized low-density lipoprotein; MOD, ox-LDL-simulated group.

AS by injuring the vascular endothelium $(24,25)$. Previous studies have suggested that ox-LDL may directly target VECs and induce apoptosis via the mitochondrial apoptotic 

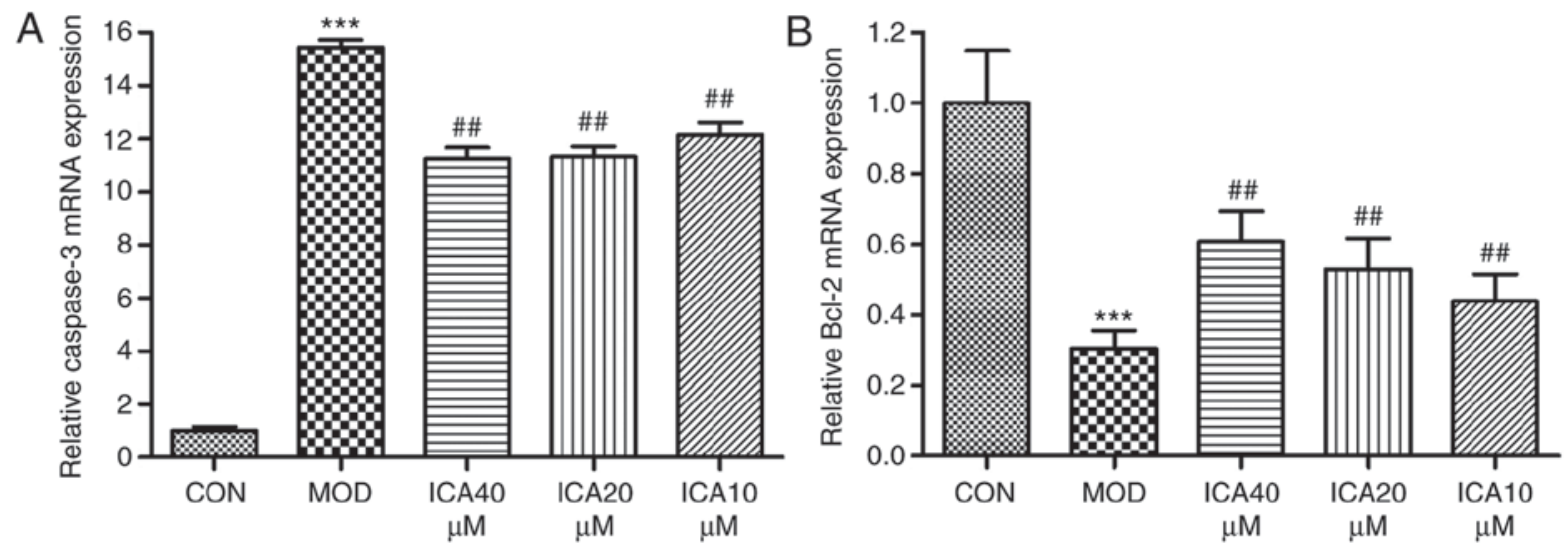

Figure 5. Regulation of Bcl-2 and caspase-3 gene expression in human vascular endothelial cells by icariin. Following pretreatment with icariin $(0,10,20$ and $40 \mu \mathrm{M})$, cells were treated for $24 \mathrm{~h}$ with ox-LDL $(100 \mu \mathrm{g} / \mathrm{ml})$. Subsequently, the expression levels of Bcl-2 and caspase-3 mRNA were determined by reverse transcription-quantitative polymerase chain reaction; as a loading control, GAPDH was used. (A) Caspase-3 mRNA expression and the ratio to the control level. (B) Bcl-2 mRNA expression and the ratio to the control level. ${ }^{* * * *} \mathrm{P}<0.001$ vs. CON; ${ }^{\# \#} \mathrm{P}<0.01$ vs. MOD. Bcl-2, apoptosis regulator Bcl-2; CON, controls; ICA, icariin-treated group; ox-LDL, oxidized low-density lipoprotein; MOD, ox-LDL-simulated group.

pathways (26-29). In addition, ox-LDL promotes the recruitment of monocytes and reactive oxygen species $(30-32)$ by upregulating $(32,33)$ and binding to the lectin-like ox-LDL receptor (23) on VECs. Caspases have been suggested to be associated with the signaling pathways underlying ox-LDL-induced apoptosis (23). Treatment with ox-LDL has been reported to result in the activation of caspase-9, thus resulting in the activation of caspase-3, the major effector caspase responsible for the destruction of various substrates, including the proteins involved in DNA repair, mRNA splicing, and DNA replication (34).

Therefore, injury to endothelial cells in the subendothelial space of the arterial wall is a critical pathological cascade in the occurrence of AS. To the best of our knowledge, the present study is the first to demonstrate that icariin may significantly suppress injury induced by ox-LDL in HUVECs. The effects of icariin were associated with increased apoptosis. Treatment with ox-LDL notably reduced HUVEC viability, increasing the apoptosis rate. Icariin significantly reversed ox-LDL-mediated effects in HUVECs.

In order to elucidate the mechanism involved in the protective influences of icariin in HUVECs, Bcl-2 and caspase-3 at the gene and protein expression levels were investigated. It has been reported that the caspase cascade served a pivotal role of in apoptosis. Caspase-3 is activated during the final step of the proapoptotic signaling pathway, while the suppression of caspase activity attenuates injury and apoptosis in HUVECs (35). The Bcl-2 family of proteins is considered to be an important family of apoptosis regulators, and include anti- and pro-apoptotic molecules $(36,37)$. The results of the present study indicated significantly reduced Bcl-2 mRNA and protein levels within ox-LDL-treated HUVECs compared with the control. Conversely, the forced expression of Bcl-2 mRNA and protein attenuated HUVEC apoptosis caused by ox-LDL, and suppressed caspase-3 activity.

In summary, the present study demonstrated that icariin inhibited HUVEC damage and apoptosis induced by ox-LDL. The antiapoptotic effects were associated with the downregulation of caspase- 3 and upregulation of $\mathrm{Bcl}-2$. The results of the present study provided additional evidence that icariin may prevent the development of AS; however, further investigation into the biological activity of icariin, including its effects on vascular smooth muscle cells or foam cells, is required.

\section{Acknowledgements}

Not applicable.

\section{Funding}

The present study was supported by grants from the National Natural Science Foundation of China (grant no. 81773934) and Natural Science of Jilin Province (grant no. 20150101221JC), and the Applied Research Project of Tonghua Normal University (grant no. 2014096).

\section{Availability of data and materials}

The datasets used and/or analyzed during the current study are available from the corresponding author on reasonable request.

\section{Authors' contributions}

YH performed the experiments and wrote the manuscript, and KL, YZ performed the cell study. HL designed the study, performed bibliographic research, drafted the manuscript and provided comments. LR and ZF designed the study, analyzed the data and wrote the manuscript.

\section{Ethics approval and consent to participate}

Not applicable.

\section{Consent for publication}

Not applicable.

\section{Competing interests}

The authors declare that they have no competing interests. 


\section{References}

1. Grundtman C and Wick G: The autoimmune concept of atherosclerosis. Curr Opin Lipidol 22: 327-334, 2011.

2. Dell'omo G, Penno G, Pucci L, Lucchesi D, Fotino C, Del Prato S and Pedrinelli R: ACE gene insertion/deletion polymorphism modulates capillary permeability in hypertension. Clin Sci (Lond) 111: 357-364, 2006.

3. Zhu F, Li C, Jin XP, Weng SX, Fan LL, Zheng Z, Li WL, Wang F, Wang WF, Hu XF, et al: Celastrol may have an anti-atherosclerosis effect in a rabbit experimental carotid atherosclerosis model. Int J Clin Exp Med 7: 1684-1691, 2014.

4. Hansson GK: Inflammation, atherosclerosis, and coronary artery disease. N Engl J Med 352: 1685-1695, 2005.

5. Yang H, Yan L, Qian P, Duan H, Wu J, Li B and Wang S: Icariin inhibits foam cell formation by down-regulating the expression of CD36 and up-regulating the expression of SR-BI. J Cell Biochem 116: 580-588, 2015.

6. Bruyndonckx L, Hoymans VY, Van Craenenbroeck AH, Vissers DK, Vrints CJ, Ramet J and Conraads VM: Assessment of endothelial dysfunction in childhood obesity and clinical use. Oxid Med Cell Longev 2013: 174782, 2013.

7. Liu YR, Chen JJ and Dai M: Paeonol protects rat vascular endothelial cells from ox-LDL-induced injury in vitro via downregulating microRNA-21 expression and TNF- $\alpha$ release. Acta Pharmacol Sin 35: 483-488, 2014

8. Xie F, Wu CF, Lai WP, Yang XJ, Cheung PY, Yao XS, Leung PC and Wong MS: The osteoprotective effect of Herba epimedii (HEP) extract in vivo and in vitro. Evid Based Complement Alternat Med 2: 353-361, 2005.

9. Hidaka S, Okamoto Y, Yamada Y, Kon Y and Kimura T: A Japanese herbal medicine, Chujo-to, has a beneficial effect on osteoporosis in rats. Phytother Res 13: 14-19, 1999.

10. Sakamoto S, Sassa S, Kudo H, Suzuki S, Mitamura T and Shinoda H: Preventive effects of a herbal medicine on bone loss in rats treated with a GnRH agonist. Eur J Endocrinol 143 $139-142,2000$

11. Xiao-Hong D, Chang-Qin X, Jian-Hua H, Wen-Jiang Z and Bing S: Icariin delays homocysteine-induced endothelial cellular senescence involving activation of the PI3K/AKT-eNOS signaling pathway. Pharm Biol 51: 433-440, 2013.

12. Zeng KW, Fu H, Liu GX and Wang XM: Icariin attenuates lipopolysaccharide-induced microglial activation and resultant death of neurons by inhibiting TAK1/IKK/NF-kappaB and JNK/p38 MAPK pathways. Int Immunopharmacol 10: 668-678, 2010.

13. Zhang G, Qin L, Sheng H, Yeung KW, Yeung HY, Cheung WH, Griffith J, Chan CW, Lee KM and Leung KS: Epimedium-derived phytoestrogen exert beneficial effect on preventing steroid-associated osteonecrosis in rabbits with inhibition of both thrombosis and lipid-deposition. Bone 40: 685-692, 2007.

14. Zhang DC, Liu JL, Ding YB, Xia JG and Chen GY: Icariin potentiates the antitumor activity of gemcitabine in gallbladder cancer by suppressing NF- $\kappa$ B. Acta Pharmacol Sin 34: 301-308, 2013.

15. Yap SP, Shen P, Li J, Lee LS and Yong EL: Molecular and pharmacodynamic properties of estrogenic extracts from the traditional Chinese medicinal herb, Epimedium. J Ethnopharmacol 113: 218-224, 2007.

16. Chen Y, Huang JH, Ning Y and Shen ZY: Icariin and its pharmaceutical efficacy: Research progress of molecular mechanism. Zhong Xi Yi Jie He Xue Bao 9: 1179-1184, 2011 (In Chinese).

17. Hu Y, Liu K, Yan M, Zhang Y, Wang Y and Ren L: Effects and mechanisms of icariin on atherosclerosis. Int J Clin Exp Med 8 3585-3589, 2015.

18. Hu Y, Liu K, Yan M, Zhang Y, Wang Y and Ren L: Icariin inhibits oxidized low-density lipoprotein-induced proliferation of vascular smooth muscle cells by suppressing activation of extracellular signal-regulated kinase $1 / 2$ and expression of proliferating cell nuclear antigen. Mol Med Rep 13: 2899-2903, 2016.

19. Hu Y, Sun B, Liu K, Yan M, Zhang Y, Miao C and Ren L: Icariin attenuates high-cholesterol diet induced atherosclerosis in rats by inhibition of inflammatory response and p38 MAPK signaling pathway. Inflammation 39: 228-236, 2016.
20. Xu CQ, Liu BJ, Wu JF, Xu YC, Duan XH, Cao YX and Dong JC: Icariin attenuates LPS-induced acute inflammatory responses: Involvement of PI3K/Akt and NF-kappaB signaling pathway. Eur J Pharmacol 642: 146-153, 2010.

21. Xu HB and Huang ZQ: Vasorelaxant effects of icariin on isolated canine coronary artery. J Cardiovasc Pharmacol 49: 207-213, 2007.

22. Livak KJ and Schmittgen TD: Analysis of relative gene expression data using real-time quantitative PCR and the 2(-Delta Delta C(T)) method. Methods 25: 402-408, 2001

23. Chen J, Mehta JL, Haider N, Zhang X, Narula J and Li D: Role of caspases in Ox-LDL-induced apoptotic cascade in human coronary artery endothelial cells. Circ Res 94: 370-376, 2004.

24. Ehara S, Ueda M, Naruko T, Haze K, Itoh A, Otsuka M, Komatsu R, Matsuo T, Itabe H, Takano T, et al: Elevated levels of oxidized low density lipoprotein show a positive relationship with the severity of acute coronary syndromes. Circulation 103: 1955-1960, 2001

25. Li D, Yang B and Mehta JL: Ox-LDL induces apoptosis in human coronary artery endothelial cells: Role of PKC, PTK, bcl-2, and Fas. Am J Physiol 275: H568-H576, 1998.

26. Giovannini C, Matarrese P, Scazzocchio B, Sanchez M, Masella R and Malorni W: Mitochondria hyperpolarization is an early event in oxidized low-density lipoprotein-induced apoptosis in Caco-2 intestinal cells. FEBS Lett 523: 200-206, 2002

27. Imanishi T, Hano T, Sawamura T, Takarada S and Nishio I: Oxidized low density lipoprotein potentiation of Fas-induced apoptosis through lectin-like oxidized-low density lipoprotein receptor-1 in human umbilical vascular endothelial cells. Circ J 66: 1060-1064, 2002.

28. Salvayre R, Auge N, Benoist H and Negre-Salvayre A: Oxidized low-density lipoprotein-induced apoptosis. Biochim Biophys Acta 1585: 213-221, 2002

29. Suo J, Zhao L, Wang J, Zhu Z, Zhang H and Gao R: Influenza virus aggravates the ox-LDL-induced apoptosis of human endothelial cells via promoting p53 signaling. J Med Virol 87: 1113-1123, 2015.

30. Cominacini L, Pasini AF, Garbin U, Davoli A, Tosetti ML, Campagnola M, Rigoni A, Pastorino AM, Lo Cascio V and Sawamura T: Oxidized low density lipoprotein (ox-LDL) binding to ox-LDL receptor-1 in endothelial cells induces the activation of NF-kappaB through an increased production of intracellular reactive oxygen species. J Biol Chem 275: 12633-12638, 2000.

31. Cominacini L, Rigoni A, Pasini AF, Garbin U, Davoli A, Campagnola M, Pastorino AM, Lo Cascio V and Sawamura T: The binding of oxidized low density lipoprotein (ox-LDL) to ox-LDL receptor-1 reduces the intracellular concentration of nitric oxide in endothelial cells through an increased production of superoxide. J Biol Chem 276: 13750-13755, 2001.

32. Li D and Mehta JL: Antisense to LOX-1 inhibits oxidized LDL-mediated upregulation of monocyte chemoattractant protein-1 and monocyte adhesion to human coronary artery endothelial cells. Circulation 101: 2889-2895, 2000.

33. Li D and Mehta JL: Upregulation of endothelial receptor for oxidized LDL (LOX-1) by oxidized LDL and implications in apoptosis of human coronary artery endothelial cells: Evidence from use of antisense LOX-1 mRNA and chemical inhibitors. Arterioscler Thromb Vasc Biol 20: 1116-1122, 2000.

34. Morishima N, Nakanishi K, Takenouchi H, Shibata T and Yasuhiko Y: An endoplasmic reticulum stress-specific caspase cascade in apoptosis. Cytochrome c-independent activation of caspase-9 by caspase-12. J Biol Chem 277: 34287-34294, 2002.

35. Luo Y, Lu S, Dong X, Xu L, Sun G and Sun X: Dihydromyricetin protects human umbilical vein endothelial cells from injury through ERK and Akt mediated Nrf2/HO-1 signaling pathway. Apoptosis 22: 1013-1024, 2017.

36. Yin H, Zhou Y, Zhu M, Hou S, Li Z, Zhong H, Lu J, Meng T, Wang J, Xia L, et al: Role of mitochondria in programmed cell death mediated by arachidonic acid-derived eicosanoids. Mitochondrion 13: 209-224, 2013.

37. Yu Y, Liu Q, Guo S, Zhang Q, Tang J, Liu G, Kong D, Li J, Yan S, Wang R, et al: 2,3,7,8-Tetrachlorodibenzo-p-dioxin promotesendothelial cell apoptosis through activation of EP3/p38MAPK/Bcl-2 pathway. J Cell Mol Med 21: 3540-3551, 2017. 